\title{
Brain death-associated pathological events and therapeutic options
}

\author{
Paweł Chudoba', A, Wojciech Krajewski2, C, D, Joanna Wojciechowska ${ }^{3, D}$, Dorota Kamińska ${ }^{4, E, F}$ \\ ${ }^{1}$ Department of Vascular, General and Transplant Surgery, Wroclaw Medical University, Poland \\ ${ }^{2}$ Department of Urology and Oncological Urology, Wroclaw Medical University, Poland \\ ${ }^{3}$ Department and Clinic of Otolaryngology Head and Neck Surgery, Wrocław Medical University, Poland \\ ${ }^{4}$ Department and Clinic of Nephrology and Transplantation Medicine, Wroclaw Medical University, Poland \\ A - research concept and design; $\mathrm{B}$ - collection and/or assembly of data; $\mathrm{C}$ - data analysis and interpretation; \\ $D$ - writing the article; $E$ - critical revision of the article; $F$ - final approval of the article
}

Address for correspondence

Wojciech Krajewski

E-mail: wk@softstar.pl

Funding sources

None declared

Conflict of interest

None declared

Received on February 24, 2016

Reviewed on August 14, 2016

Accepted on September 6, 2016
DOI

10.17219/acem/65068

\section{Copyright}

Copyright by Author(s)

This is an article distributed under the terms of the

Creative Commons Attribution Non-Commercial License

(http://creativecommons.org/licenses/by-nc-nd/4.0/)

\section{Abstract}

Background. At present, organ transplantation is the most efficient treatment of end-stage failure of various organs, including the heart, lungs, pancreas, intestines, kidney, and liver. Despite the efforts to use organs from living donors or from donors after circulatory death, most of the organs are recovered from brain dead (BD) donors.

Methods. The Medline and Web of Science databases were searched without time limit on November 2015 using the terms "brain dead donor" and "deceased donor" in conjunction with "transplantation", "graft", "organ", "hemodynamic", "hormonal", or "management". The search was limited to the English, Polish and Spanish literature. Articles that did not address the topics were excluded and the full text of the remaining articles was reviewed.

Results. It is well established that brain death is associated with a cascade of hemodynamic, inflammatory, and immunologic events that affect the outcome of transplanted organs. Proper management of the potential organ donor may help increase the supply of organs for transplantation. However, because there is a lack of good quality evidence, it is difficult to establish specific BD donor management guidelines.

Conclusions. In this paper we present a review of studies and literature concerning the detrimental impact of donor brain death on graft function. We present pathologic changes that take place after brain death, their influence on graft quality and therapeutic solutions to enhance transplanted organ function.

Key words: transplantation, brain dead donor, deceased donor, organ management 


\section{Introduction}

At present, organ transplantation is the most efficient treatment of end-stage failure of various organs, including the heart, lungs, pancreas, intestines, kidney, and liver. Despite the efforts to use organs from living donors or from donors after circulatory death, most of the organs are recovered from brain dead (BD) donors. Persistent donor organ shortage causes extended waiting lists, and a substantial percentage of patients die while waiting for an organ. As a result, a move toward accepting suboptimal donors is increasing.

Despite improvements in organ preservation, reduction of cold ischemia time, better organ allocation and tailored recipient pharmacotherapy, the outcomes reached with organs from living donors are far superior when compared to grafts procured from deceased donors. ${ }^{1}$

\section{Methods}

The Medline and Web of Science databases were searched without a time limit on November 2015 using the terms "brain dead donor" and "deceased donor" in conjunction with "transplantation", "graft", "organ", "hemodynamic", "hormonal", or "management". Boolean operators (NOT, AND, OR) were also used in succession to narrow and broaden the search. Autoalerts in Medline were also run, and reference lists of original articles, review articles, and book chapters were searched for further eligible articles. The search was limited to the English, Polish and Spanish literature. Articles that did not address the topics were excluded, and the full text of the remaining articles was reviewed.

In this paper we present a review of studies and literature concerning the detrimental impact of donor brain death on graft function. We present pathologic changes that take place after brain death, their influence on graft quality, and therapeutic solutions to enhance transplanted organ function.

\section{Discussion}

The function of grafts from BD donor's graft function is affected by various factors. Characteristics of a donor, such as gender, age, race, serum creatinine before harvesting, history of comorbidities (e.g., hypertension, diabetes, HCV status), and the cause of death all impact organ function. Additionally, because of logistical reasons, cold ischemia time is usually longer in deceased donor transplantation. Deceased donors are frequently older than living donors; nevertheless, it has been shown that survival rates of living donor organs are better in every age category, compared to BD's organs. ${ }^{2}$ What is more, average HLA matching is usually worse in living donation.
This suggests that weak survival of grafts from BD donors cannot be solely caused by donor characteristics and differences in immunogenicity.

By definition, BD is the irreversible loss of brain and brain stem function. It is frequently caused by a cerebral hemorrhage, hypoxia, or/and metabolic dysregulation. According to the American Academy of Neurology 2010 guidelines, the BD definition is composed of the following criteria: unawareness of and unresponsiveness to external stimuli, no spontaneous movements or breathing and absence of brainstem reflexes. Attention is needed for states such as high cervical cord injury, drug intoxication, hypothermia, fulminant Guillain-Barré syndrome, and hypotension. In some cases, ancillary tests such as EEG, transcranial Duplex-ultrasound, digital subtraction cerebral angiography or nuclear cerebral blood flow scanning are required to confirm $\mathrm{BD} .^{3}$

As a result of BD, cascade of hemodynamic (hypotension, arrhythmias), hormonal (diabetes insipidus, hypoglycemia), pulmonary (pulmonary edema, ventilator-induced lung injury), metabolic, and inflammatory changes is unleashed. This all leads to impaired graft function and accelerated immunogenicity, and is associated with impaired patient as well as graft survival rates.

\section{Hemodynamic changes}

After cerebral hemorrhage or injury, the increased intracranial pressure (ICP) causes damage to the cerebrum tissue, leading to a great stimulation of the parasympathetic system and to decreased systemic blood pressure. Progressive elevation of ICP results in herniation of the brain stem through the foramen magnum, which is related to arterial compression and occlusion with advancing brain ischemia. When the pons becomes ischemic, the sympathetic nervous system is activated. Simultaneous sympathetic and parasympathetic activation causes the Cushing reflex - the phenomenon composed of multiple disturbances in the physiology, such as bradycardia, hypertension, and an irregular breathing pattern.

After the vagal cardiomotor nucleus has become ischemic, parasympathetic stimulation decreases. Further, uncontrolled systematic and myocardial catecholamine release causes an increase in the heart rate and leads to vasoconstriction with increased vascular resistance and blood pressure. This so-called "catecholamine storm" is considered to be the ultimate effort to restore cerebral perfusion. During that process, serum catecholamine levels are 100-1000-fold higher compared to normal values, and the scale of catecholamine release is related to the severity of a brain injury. The catecholamine-induced vascular resistance can reach levels fourfold higher than normal values. This causes a significant drop in organ perfusion and leads to ischemic damage of potential grafts. An increase in pulmonary vascular resistance leads 
to escalated right ventricular pressure and dysfunction. Differences in pulmonary and systemic vascular resistance and blood flow lead to pooling of blood in the lungs and neurogenic pulmonary edema.

Finally, due to ischemia of the spinal cord, sympathetic stimulation decreases, leading to a decline in blood pressure, heart rate, cardiac output, and finally, general hypoperfusion. ${ }^{4}$

\section{Hormonal changes}

The hormonal changes after BD are generally related to the hypothalamus and to anterior and posterior pituitary gland failure. Following BD, the hypothalamus and pituitary ischemia, as well as the critical illness stress response, produce hormonal production alternations. Endocrine changes vary in timing and severity. It has been demonstrated in animal models with BD that circulating catecholamine levels increase during the first $15 \mathrm{~min}$ after BD. Afterwards, epinephrine and norepinephrine concentrations decline, but dopamine concentrations increase up to $90 \mathrm{~min}$ after BD. Adrenocorticotropic hormone $(\mathrm{ACTH})$, cortisol and vasopressin levels decrease significantly by $45 \mathrm{~min}$ after $\mathrm{BD} .{ }^{5}$ Following the onset of $\mathrm{BD}$, plasma levels of free 3,3,5-triiodo-L-thyronine (T3) gradually decrease, whereas the levels of thyroid stimulating hormone, free thyroxine, reverse T3, and cortisol are variable. ${ }^{6,7}$

\section{Treatment}

Because of the growing demand for organs, there is an increasing necessity to optimize donation potential in $\mathrm{BD}$ patients. An optimized management of BD patients can increase the amount of harvested grafts.

The main goals include the maintenance of proper body temperature, adequate oxygenation, sufficient circulating volume, cardiovascular stability, and adequate urine output.

In the past, easily remembered series of goals was the "rule of 100 " - systolic arterial pressure greater than $100 \mathrm{~mm} \mathrm{Hg}$, urine output greater than $100 \mathrm{~mL} / \mathrm{h}, \mathrm{PaO} 2$ greater than $100 \mathrm{~mm} \mathrm{Hg}$, and hemoglobin concentration of $100 \mathrm{~g} \backslash \mathrm{L}$. Later, new blood sugar 100\% normal goal was added. ${ }^{8}$

\section{Cardiovascular support and fluid management}

\section{Fluids}

The first step in managing a donor with vasoplegia and hypotension is to preserve an adequate intravascular volume. There is a lack of reliable evidence proving which type of fluid is better in the management of a BD donor.
The choice of fluid and administration rate should result from previous therapy, incidence of diabetes insipidus polyuria, and considerations of the effects of excessive fluids on the respiratory system.

It was shown that restrictive fluid management can prevent fluid overload and lung neurogenic edema, and can increase the rate of lung grafts available for transplant supports. Restrictive fluid management may provide adequate perfusion to vital organ systems even with a CVP $<6 \mathrm{~mm} \mathrm{Hg}$, yet, according to actual Eurotransplant guidelines, CVP should be maintained between 6 and $10 \mathrm{~mm} \mathrm{Hg}{ }^{9}$

In case of active bleeding, hemoglobin level below $9.6 \mathrm{~g} / \mathrm{dL}$ or hematocrit level below $20 \%$, blood product replacement should also be utilized.

Previously, it has been suggested that the use of crystalloids, in contrast to colloid solutions, may be deleterious to lung grafts because of fluid overload; however, the available randomized control trials (RCTs) do not support these findings. ${ }^{10}$ One study suggested that hydroxyethylstarch (HES) impairs immediate renal function in kidney-transplant recipients. Another study did not find any differences between liver donor groups when HES was used in comparison with crystalloid solutions. ${ }^{11,12}$ Nevertheless, these results may be related to the use of older HES formulations. $^{13}$

\section{Cardiovascular support}

After the BD event and following "catecholamine storm", there is a constant reduction in circulating catecholamines levels. Various guidelines support the administration of inotropes or vasopressors to stabilize potential deceased heart-beating donors. However, due to the absence of high quality evidence, the consensus on the specific agent or combination therapy is lacking. According to Eurotransplant guidelines, regardless of the exact treatment strategy, a mean arterial pressure greater than $90 \mathrm{~mm} \mathrm{Hg}$, urine output greater than $1 \mathrm{~mL} / \mathrm{kg} / \mathrm{h}$ and pulmonary capillary wedge pressure of $10-15 \mathrm{~mm} \mathrm{Hg}$ ought to be sustained.

It has been previously shown that dopamine or norepinephrine BD donor treatment is an independent beneficial factor in renal transplant outcome. ${ }^{14}$

More recently, it has been proven in RCTs that donor treatment with dopamine causes a reduction in dialysis requirement after kidney transplantation. In another study, authors stated that dopamine treatment clearly improves renal histology. However, no clinically significant impact on graft or patient survival was noted. ${ }^{15,16}$

Furthermore, in a recent meta-analysis of septic shock patients, it was shown that dopamine administration is associated with greater mortality and a higher incidence of arrhythmic events compared to norepinephrine therapy. ${ }^{17}$ On that basis it can be concluded that norepinephrine is safer when compared with dopamine. 
However, in a small study by Stoica et al., authors stated that the use of high doses of norepinephrine in BD donors is associated with increased cardiac graft dysfunction and higher mortality in recipients. ${ }^{18}$

In other retrospective analysis of 936 patients, it was shown that neither norepinephrine nor dopamine pre-treatment of potential heart donors showed superior overall survival. What is more, in a sub-population of long-term survivors, norepinephrine pre-treatment was associated with better survival in a rather small cohort of heart transplant recipients. ${ }^{19}$

Nevertheless, high doses of catecholamines can reduce renal and hepatic perfusion. Additionally, it was suggested from animal studies that elongated catecholamine administration could lead to a reduction in the myocardial beta-adrenergic receptors expression density and may potentially influence heart graft function. ${ }^{20}$ According to actual Eurotransplant guidelines, catecholamines use in the BD donor management should be avoided whenever possible. However, catecholamines may exert a beneficial effect when administered after organ recovery. It was demonstrated that during adult liver transplantation surgery, the administration of either $10 \mu \mathrm{g}$ of epinephrine or $100 \mu \mathrm{g}$ of phenylephrine at the reperfusion time is an efficient method for reducing the occurrence of postreperfusion syndrome and the need for vasoactive support. $^{21}$

\section{Hormonal management}

Hormonal substitution therapy is a subject of intense debate. It has been shown in a retrospective analysis of more than 10,000 consecutive donors that aggressive pharmacologic therapy results in more organs suitable for transplantation. ${ }^{22}$ Nevertheless, other authors do not to confirm these observations. ${ }^{23}$

At present, despite low-quality evidence, various guidelines recommend hormonal substitution therapy that include the administration of thyroid hormones (T3 or T4), corticosteroids, vasopressin (ADH), and insulin.

\section{Thyroid hormones T3/T4}

It has been suggested that diminished thyroid hormone concentration after BD causes hemodynamic instability, leading to a decline of myocardial energy stores and a change from aerobic to anaerobic metabolism. ${ }^{24}$

Experimental studies have demonstrated enhanced cardiac function after thyroid hormonal therapy in animal model. Various retrospective analyses state that thyroid hormonal administration may improve cardiac function and increase the number of organs transplanted per donor. ${ }^{23}$ It was shown that T3 administration before the induction of $\mathrm{BD}$ decreases liver cell injury and apoptosis in animal model. ${ }^{25}$ Recent retrospective analysis of 66,629 donors showed that T3/T4 therapy results in more transplantable organs, yet with no detriment to post-transplantation graft survival. ${ }^{26}$

Two meta-analyses of thyroid hormone effectiveness were published lately. The authors of both studies stated that the majority of available studies were of low quality and were heterogeneous in nature. The most interesting finding was that the all nonrandomized reports concluded that thyroid hormone therapy was beneficial. On the contrary, every randomized controlled studies stated that there was no clinical benefit, such as posttransplant function improvement, circulating troponin levels reduction or hemodynamic stability progress. Additionally, the analysis of the 4 placebo-controlled studies failed to identify any benefit of thyroid hormone on donor cardiac index or vasoactive drug requirements. ${ }^{23,27,28}$

\section{Corticosteroids}

BD results in hypothalamic-pituitary-adrenal axis disruption. Although cortisol secretion was observed in some potential donors to be reduced, other authors state that cortisol levels after BD can be normal or high.

It is hypothesized that corticosteroids supplementation may increase hemodynamic stability, reduce inflammatory response and, therefore, improve clinical outcomes in brain dead donors.

In the recently published systematic review, authors shown no clear clinical benefit based on RTCs from the administration of corticosteroids to potential donors. On the contrary, observational studies have shown advantageous outcomes of the administration of corticosteroids on hemodynamic and oxygenation parameters. Moreover, most of observational studies found better outcomes in organ recovery when corticosteroids were used. ${ }^{29}$ However, the majority of studies evaluated only methylprednisolone, and the quality of the included studies was poor, with high risk of bias identified in the majority.

Other new, multicenter, prospective study showed that hydrocortisone administration during the resuscitation of a brain-dead donor is associated with decreased vasopressor doses need to maintain a stable hemodynamic state. The authors state that, despite no observed benefits of the steroid administration on primary function recovery of transplanted grafts, the administration of glucocorticoids should be a part of the resuscitation management of deceased donors with hemodynamic instability. ${ }^{30}$

Concerns relate also to steroid doses. One recent study compared the use of low-dose hydrocortisone with highdose MP. Authors demonstrated that lower-dose corticosteroid protocol did not worsen donor pulmonary or cardiac function, and insulin requirements and glycemic control were improved. ${ }^{31}$ 


\section{Vasopressin}

Main vasopressin (ADH) physiological effect, i.e., water retention, is achieved by increased urine osmolarity and decreased water excretion. Diabetes insipidus (DI) (diuresis $>5 \mathrm{~mL} / \mathrm{kg} / \mathrm{BW} / \mathrm{h}$, urine specific gravity <1005) caused by $\mathrm{ADH}$ deficit applies to $80 \%$ of $\mathrm{BD}$ donors. It is caused by the rapid depletion of ADH secretion because of pituary gland ischemic failure and results in intensified diuresis, followed by hypovolemia, hyperosmolarity, and hypernatremia. Additionally, the downregulation of aquaporin- 2 channels caused by BD aggravates the decline of hemodynamic stability. ${ }^{32}$

To maintain adequate blood pressure, hormonal replacement therapy with vasopressin is advised. ${ }^{33}$ Lowdose vasopressin therapy, when compared to fluid volume replacement, improves blood pressure, decreases inotrope requirements and preserves levels of myocardial high energy phosphates, and allows for the reduction of catecholamine supply. ${ }^{4}$ Administration of only crystalloid solutions results in the exacerbation of neurogenic pulmonary edema and frustrates pulmonary procurement. In therapy, both vasopressin and desmopressin can be used. Intravenous, subcutaneous, intramuscular or intranasal administration of desmopresin results in $\mathrm{V} 2$ receptors activation. $\mathrm{ADH}$ infusion results in both the V1 and V2 receptors activation and, therefore, either vasoconstriction and water retention. Some authors suggest the use of terlipressin, a synthetic analog of vasopressin characterized by greater selectivity for the V1 receptor than vasopressin. ${ }^{34}$

In a recent meta-analysis, the authors demonstrated that the use of desmopressin is safe and useful to limit the harmful effects of profuse polyuria; however, it was not associated with better kidney graft outcomes. ${ }^{23}$

In other study, it was demonstrated that vasopressin compromised both the systemic and superior mesenteric artery blood flow. It was also associated with inadequate oxygen delivery. These adverse effects were not observed with dopamine. ${ }^{35}$

Nevertheless, it was shown that chronic V2-receptor stimulation was independently associated with a decrease in the calculated glomerular filtration rate over a median follow-up time of 3.6 years after kidney transplantation. However, it is suspected that chronic V2-receptor stimulation increases renal plasma flow and induces hyperfiltration, which in turn causes renal hypertrophy and proteinuria. ${ }^{36}$

\section{Insulin}

Hyperglycemia and insulin resistance are common in potential BD donors. Additionally, hyperglycemia in often aggravated because of common steroid administration.

It was shown that higher average glucose values and greater variability in glucose concentrations were associated with worse post-transplant renal function. ${ }^{37}$
Therefore, it is advised to aggressively treat hyperglycemia episodes targeting control levels between 120 and $180 \mathrm{mg} / \mathrm{dL}$. Hyperglycemia management enhances the hemodynamic performance of myocardium, reduces myocardial injury, and diminishes inotrope requirements by optimizing substrate utilization, reducing toxic circulating free fatty acids, direct inotropic and anti-apoptotic effects of insulin, as well as the potential to improving the calcium handling and beta-adrenergic properties of the myocyte. ${ }^{4}$ Intensive insulin therapy in intensive care unit (ICU) patients is also associated with the prevention of newly acquired kidney injury, accelerated weaning from mechanical ventilation and the reduction of the inflammatory response. ${ }^{38}$

\section{Mechanical ventilation}

The best quality evidence in the management of $\mathrm{BD}$ organ donor refers to mechanical ventilation. Lungs in $\mathrm{BD}$ patients may be damaged because ventilator-induced injury, trauma, aspiration pneumonitis, and fat emboli. Formerly, high tidal volumes and low positive end-expiratory pressure (PEEP) were used in ICUs for lung recruitment. Recently, it has been suggested that lung injury from $\mathrm{BD}$ donors is similar to the injury seen in acute lung injury and acute respiratory distress syndrome. Therefore, modern acute lung injury ventilator strategy was adapted also in the case of BD patients. Protective ventilatory strategy (peak pressure $<35 \mathrm{~mm} \mathrm{Hg}$, tidal volumes of $6-8 \mathrm{~mL} / \mathrm{kg}$, PEEP of 5-10 $\mathrm{cm} \mathrm{H}_{2} \mathrm{O}$, apnea tests performed by using continuous positive airway pressure, closed circuit for airway suction) increased the number of eligible and harvested lungs compared to a conventional strategy. Moreover, avoiding high-inspired oxygen concentrations may decrease the risk of bronchiolitis obliterans syndrome in lung recipients. ${ }^{39}$

\section{Temperature}

One of the consequences of $\mathrm{BD}$ is body temperature dysregulation. ${ }^{40}$ Actual practice includes active warming to maintain a donor's body temperature higher than $35^{\circ} \mathrm{C}$. In a 5 -year retrospective analysis, it has been shown that hypothermia (temperature $<36^{\circ} \mathrm{C}$ ) was associated with a significant decline in the eligibility for organ donation. Patients suffering hypothermia were less likely to donate solid organs, and when they did, they donated fewer organs per donor. Furthermore, patients in hypothermia had higher fresh frozen plasma, vasopressin, and dopamine requirements. ${ }^{41}$

On the other hand, some authors hypothesize that rapid cooling with ice-cold fluid just before organ harvesting may slow down organ metabolism and oxygen consumption, improve tolerance to ischemia, and improve organ viability in some patients. ${ }^{42}$ 
In a recent prospective, randomized, controlled trial on 394 donors, it was shown that a noninvasive temperature management protocol aimed at achieving mild hypothermia $\left(34-35^{\circ} \mathrm{C}\right)$ decreased the rate of delayed graft function. This effect was particularly visible in kidney recipients from the highest-risk donors. ${ }^{43}$

Table 1. Brain dead donors management goals

\begin{tabular}{|c|c|}
\hline Parameter & Values \\
\hline Temperature & $34-36^{\circ} \mathrm{C}$ \\
\hline $\begin{array}{l}\text { Ventilation } \\
\text { parameters }\end{array}$ & $\begin{array}{c}\text { peak pressure }<35 \mathrm{~mm} \mathrm{Hg} \\
\text { tidal volumes of } 6-8 \mathrm{~mL} / \mathrm{kg} \\
\text { PEEP of } 5-10 \mathrm{~cm} \mathrm{H} \mathrm{H}_{2} \mathrm{O}\end{array}$ \\
\hline $\begin{array}{l}\text { Hemoglobin and } \\
\text { hematocrit levels }\end{array}$ & $\begin{array}{c}\text { hemoglobin }>9.6 \mathrm{~g} / \mathrm{dL} \\
\text { hematocrit }>20 \%\end{array}$ \\
\hline $\begin{array}{l}\text { Hemodynamic } \\
\text { parameters }\end{array}$ & $\begin{array}{l}\text { CVP: } 6-10 \mathrm{~mm} \mathrm{Hg} \\
\text { mean arterial pressure }>90 \mathrm{~mm} \mathrm{Hg} \\
\text { urine output }>1 \mathrm{~mL} / \mathrm{kg} / \mathrm{h} \\
\text { pulmonary capillary wedge pressure: } \\
10-15 \mathrm{~mm} \mathrm{Hg}\end{array}$ \\
\hline $\begin{array}{l}\text { Blood glucose } \\
\text { level }\end{array}$ & $120-180 \mathrm{mg} / \mathrm{dL}$ \\
\hline
\end{tabular}

\section{New insights}

\section{Erythropoietin/carbomylated erythropoietin}

Erythropoietin (EPO) was shown to have neuroprotective activity after brain ischemia by diminishing brain cell apoptosis and necrosis, reducing brain edema, and decreasing the expression of several proinflammatory genes. What is more, EPO stimulates the proliferation of cardiomyocytes and decreases myocardial infarction size. It also helps to reduce systemic inflammation and to preserve endothelial integrity. In the kidney, EPO leads to increased heat shock protein expression, decreases apoptosis after ischemia/reperfusion, and decreases infiltration of polymorphonuclear cells. It was proven that kidney function decreases almost by $50 \%$ after brain death, but may be fully restored after treatment with EPO. However, the benefits of erythropoietin are accompanied by unwanted overstimulation of the bone marrow, inducing a prothrombotic state. Because of that, carbamylated erythropoietin (CEPO), a modified derivative of EPO that is free from erythropoietic properties, was synthesized. It was shown in animal model that CEPO can be used as renoprotective agent for clinical intervention during donor management and before retrieval, followed by ischemia/reperfusion injury. ${ }^{44,45}$

\section{Anti-thymocyte immunoglobulin}

Anti-thymocyte immunoglobulin (ATG) is a purified fraction of IgG from the rabbit serum immunized against human thymocytes, and is administered for the prevention of post-transplant rejection.
It was shown in an animal model that ATG administration to potential BD donors may ameliorate renal injury and, therefore, improve graft function.

Animals treated with ATG showed a significant decrease in acute tubular necrosis score and creatinine values, a significant increase in IL-10 expression, and a significantly lower in situ expression of monocyte chemotactic protein $1 .{ }^{46}$ In another study, authors found statistically significant attenuation of histological damage in lungs, as well as a tendency of attenuation in heart graft and small bowel when ATG was administered to donors. ${ }^{47}$

\section{Exendin-4}

Exendin-4 (Ex-4), a glucagon-like peptide-1 (GLP1) analogue, holds anti-inflammatory and cytoprotective properties. It was demonstrated in a recent study that Ex-4 administration to brain dead rats reduces BD-induced liver damage. In their earlier study, authors also showed that donor treatment with Ex-4 increases viability and function of pancreatic islets after isolation.

The authors state that Ex-4 in the clinical practice may promote not only liver, but also pancreatic islet transplantation outcomes. ${ }^{48,49}$

\section{Vagus nerve stimulation}

It is a well-known fact that the vagus nerve supplies parasympathetic fibers to many visceral organs. Additionally, it is involved in the cholinergic anti-inflammatory pathway, also known as inflammatory reflex. Activation of vagus nerve leads to acetylcholine release, which binds to nicotinic cholinergic receptor found on macrophages. It results in macrophage activation inhibition and decrease of TNF synthesis. The cholinergic anti-inflammatory reflex is considered putative therapeutic target. Experimental studies have shown the efficacy of cholinergic agonists in sepsis, septic shock, and ischemia reperfusion injury models.

The vagus nerve electrostimulation may be also a way to improve transplantation results in renal recipients. It was shown in animal model, that vagal stimulation of BD donors improved survival of the recipients, improved renal function in the recipients, and significantly reduced intimal arteritis, tubulitis and chronic tubulopathy in the grafts. ${ }^{50,51}$

\section{Gaseous modulators}

\section{Nitric oxide}

Supportive BD donor management such as ventilation or administration of vasoactive agents may have a small ability to preserve end-organ oxygen delivery, which is primarily a function of local tissue perfusion. Local perfusion 
is in part self-regulated through NO bioactivity, and BD-induced interruption of endocrine NO bioactivity may result in the tissue ischemia and organ damage. It was shown lately that inhalation of BD swine with the S-nitrosylating agent ethyl nitrite (ENO) was an effective method to attenuate brain death-induced reductions in S-nitrosohemoglobin (SNO-Hb) concentrations, to maintain tissue oxygenation, and to reduce tissue injury, inflammation, and organ damage. ${ }^{52}$ It was also demonstrated that NO inhalation may be helpful in the improvement of hypoxemia caused by neurogenic pulmonary edema (NPE) in BD organ donors. ${ }^{53}$

Another compound, tetrahydrobiopterin (H4B), is an essential co-factor for all NO synthases isoforms. It was observed in multiple studies in animal models that H4B BD treatment ameliorates ischemia-reperfusion injury (IRI) and microcirculation derangements and significantly improves recipient survival following various organs transplantations. ${ }^{54}$

\section{Hydrogen sulfide}

Hydrogen sulfide $\left(\mathrm{H}_{2} \mathrm{~S}\right)$ is involved in various homeostatic functions, such as blood pressure control, electrolyte balance and apoptosis, and regulates various pathological mechanisms, including oxidative stress and inflammation. It is suggested that $\mathrm{H}_{2} \mathrm{~S}$ has a protective effect against ischemia-reperfusion injury, and $\mathrm{H}_{2} \mathrm{~S}$ therapy can present a promising approach in organ protection. ${ }^{55}$

It was shown in an animal model that during reperfusion, lungs pretreated with inhaled $\mathrm{H}_{2} \mathrm{~S}$ exhibited better oxygenation, ventilation, lower pulmonary artery pressures, and lower reactive oxygen species levels. ${ }^{56}$

It was also shown that $\mathrm{H}_{2} \mathrm{~S}$ treatment during cold storage of kidneys and livers effectively mitigates organ IRI improving allograft function and survival, and decreases allograft injury. ${ }^{57,58}$

\section{Carbon nanoxide}

Carbon monoxide $(\mathrm{CO})$ is endogenously synthesized in human cells in heme metabolic pathways. It is hypothesized that $\mathrm{CO}$ protects against cellular injury by relaxing the blood vessels, inhibiting platelet aggregation and derepressing fibrinolysis. What is more, $\mathrm{CO}$ reduces IRI and inflammation responses, inhibits endothelial and epithelial cells apoptosis, and diminishes smooth muscles, fibroblasts and T lymphocytes proliferation. There is a significant amount of preclinical data to support the hypothesis that $\mathrm{CO}$ donors, organs or recipients' treatment can prevent graft function deterioration. ${ }^{59,60}$

\section{Conclusions}

Nowadays, the majority of organs for transplantation originate from $\mathrm{BD}$ donors. It is well established that brain death is associated with a cascade of hemodynamic, inflammatory, and immunologic events that affect the outcome of transplanted organs. Proper management of the potential organ donor may help increase the supply of organs for transplantation. We presented the current therapeutic approach and a number of new concepts, which in the future will reduce the gap between the demand and supply of organs.

However, because of a lack of good quality evidence, it is difficult to establish specific BD donor management guidelines. Moreover, well-designed research is needed to understand the mechanisms of injury and repair during massive cerebral injury and to identify optimal donor management strategies.

\section{References}

1. Terasaki PI, Cecka JM, Gjertson DW, Takemoto S. High survival rates of kidney transplants from spousal and living unrelated donors. N Engl J Med. 1995;333:333-336.

2. Rowe TA, Huded J, McElroy L, Ladner DP, Lindquist LA. The evolution of living kidney donation and transplantation in older adults. J Am Geriatr Soc. 2015;63:2616-2620.

3. Wijdicks EF, Varelas PN, Gronseth GS, Greer DM. Evidence-based guideline update: Determining brain death in adults. Report of the Quality Standards Subcommittee of the American Academy of Neurology. Neurology. 2010;74:1911-1918.

4. Bos EM, Leuvenink HG, van Goor H, Ploeg RJ. Kidney grafts from brain dead donors: Inferior quality or opportunity for improvement? Kidney Int. 2007;72:797-805.

5. Chen EP, Bittner HB, Kendall SW, Van Trigt P. Hormonal and hemodynamic changes in a validated animal model of brain death. Crit Care Med. 1996;24:1352-1359.

6. Novitzky D, Cooper DK, Rosendale JD, Kauffman HM. Hormonal therapy of the brain-dead organ donor: Experimental and clinical studies. Transplantation. 2006;82:1396-1401.

7. Taniguchi S, Kitamura S, Kawachi K, Doi Y, Aoyama N. Effects of hormonal supplements on the maintenance of cardiac function in potential donor patients after cerebral death. Eur J Cardiothorac Surg. 1992;6:96-102.

8. Gelb AW, Robertson KM. Anaesthetic management of the brain dead for organ donation. Can J Anaesth. 1990;37:806-812.

9. Minambres $E$, Rodrigo $E$, Ballesteros $M A$, et al. Impact of restrictive fluid balance focused to increase lung procurement on renal function after kidney transplantation. Nephrol Dial Transplant. 2010;25:2352-2356.

10. Pennefather SH, Bullock RE, Dark JH. The effect of fluid therapy on alveolar arterial oxygen gradient in brain-dead organ donors. Transplantation. 1993;56:1418-1422.

11. Cittanova ML, Leblanc I, Legendre C, Mouquet C, Riou B, Coriat P. Effect of hydroxyethylstarch in brain-dead kidney donors on renal function in kidney-transplant recipients. Lancet. 1996;348:1620-1622.

12. Randell T, Orko R, Hockerstedt K. Peroperative fluid management of the brain-dead multiorgan donor. Acta Anaesthesiol Scand. 1990;34:592-595.

13. Blasco V, Leone M, Antonini F, Geissler A, Albanese J, Martin C. Comparison of the novel hydroxyethylstarch 130/0.4 and hydroxyethylstarch 200/0.6 in brain-dead donor resuscitation on renal function after transplantation. Br J Anaesth. 2008;100:504-508.

14. Schnuelle P, Berger S, de Boer J, Persijn G, van der Woude FJ. Effects of catecholamine application to brain-dead donors on graft survival in solid organ transplantation. Transplantation. 2001;72:455-463.

15. Schnuelle P, Gottmann U, Hoeger S, et al. Effects of donor pretreatment with dopamine on graft function after kidney transplantation: A randomized controlled trial. JAMA. 2009;302:1067-1075.

16. Fontana J, Yard B, Stamellou E, et al. Dopamine treatment of braindead Fisher rats improves renal histology but not early renal function in Lewis recipients after prolonged static cold storage. Transplant Proc. 2014;46:3319-3325. 
17. de Backer D, Aldecoa C, Njimi H, Vincent JL. Dopamine versus norepinephrine in the treatment of septic shock: A meta-analysis. Crit Care Med. 2012:40:725-730.

18. Stoica SC, Satchithananda DK, White PA, Parameshwar J, Redington AN, Large SR. Noradrenaline use in the human donor and relationship with load-independent right ventricular contractility. Transplantation. 2004;78:1193-1197.

19. von Ziegler F, Helbig S, KreissI N, Meiser B, Becker A, Kaczmarek I. Norepinephrine versus dopamine pretreatment of potential heart donors: Impact on long-term outcome. Ann Transplant. 2013;18:320-326.

20. Sakagoshi N, Shirakura R, Nakano S, Taniguchi K, Miyamoto Y, Matsuda $\mathrm{H}$. Serial changes in myocardial beta-adrenergic receptor after experimental brain death in dogs. J Heart Lung Transplant. 1992;11:1054-1058.

21. Ryu HG, Jung CW, Lee HC, Cho YJ. Epinephrine and phenylephrine pretreatments for preventing postreperfusion syndrome during adult liver transplantation. Liver Transpl. 2012;18:1430-1439.

22. Rosendale JD, Kauffman HM, McBride MA, et al. Aggressive pharmacologic donor management results in more transplanted organs. Transplantation. 2003;75:482-487.

23. Rech TH, Moraes RB, Crispim D, Czepielewski MA, Leitao CB. Management of the brain-dead organ donor: A systematic review and meta-analysis. Transplantation. 2013;95:966-974.

24. Salim A, Vassiliu P, Velmahos GC, et al. The role of thyroid hormone administration in potential organ donors. Arch Surg. 2001;136:1377-1380.

25. Rebolledo RA, van Erp AC, Ottens PJ, Wiersema-Buist J, Leuvenink HG, Romanque P. Anti-apoptotic effects of 3,3',5-triiodo-L-thyronine in the liver of brain-dead rats. PLoS One. 2015;10:e0138749.

26. Novitzky D, Mi Z, Sun Q, Collins JF, Cooper DK. Thyroid hormone therapy in the management of 63,593 brain-dead organ donors: A retrospective analysis. Transplantation. 2014;98:1119-1127.

27. Donly BC, Edgar CD, Adamski FM, Tate WP. Frameshift autoregulation in the gene for Escherichia coli release factor 2: Partly functional mutants result in frameshift enhancement. Nucleic Acids Res. 1990;18:6517-6522.

28. Joseph B, Aziz H, Pandit V, et al. Levothyroxine therapy before brain death declaration increases the number of solid organ donations. J Trauma Acute Care Surg. 2014;76:1301-1305.

29. Dupuis S, Amiel JA, Desgroseilliers $M$, et al. Corticosteroids in the management of brain-dead potential organ donors: A systematic review. Br J Anaesth. 2014;113:346-359.

30. Pinsard M, Ragot S, Mertes PM, et al. Interest of low-dose hydrocortisone therapy during brain-dead organ donor resuscitation: The CORTICOME study. Crit Care. 2014;18(4):R158.

31. Dhar R, Cotton C, Coleman J, et al. Comparison of high- and lowdose corticosteroid regimens for organ donor management. J Crit Care. 2013;28:e111-117

32. Schuurs TA, Gerbens F, van der Hoeven JA, et al. Distinct transcriptional changes in donor kidneys upon brain death induction in rats: Insights in the processes of brain death. Am J Transplant. 2004;4:1972-1981.

33. Callahan DS, Neville A, Bricker $S$, et al. The effect of arginine vasopressin on organ donor procurement and lung function. J Surg Res. 2014;186:452-457.

34. Piazza O, Scarpati G, Rispoli F, lannuzzi M, Tufano R, De Robertis E. Terlipressin in brain-death donors. Clin Transplant. 2012;26(6):E571-575.

35. Martikainen TJ, Kurola J, Karja V, Parviainen I, Ruokonen E. Vasopressor agents after experimental brain death: Effects of dopamine and vasopressin on vitality of the small gut. Transplant Proc 2010;42:2449-2456.

36. Meijer E, Bakker SJ, de Jong PE, et al. Copeptin, a surrogate marker of vasopressin, is associated with accelerated renal function decline in renal transplant recipients. Transplantation. 2009;88:561-567.

37. Blasi-lbanez A, Hirose R, Feiner J, et al. Predictors associated with terminal renal function in deceased organ donors in the intensive care unit. Anesthesiology. 2009;110:333-341.

38. van den Berghe $G$, Wilmer A, Hermans $G$, et al. Intensive insulin therapy in the medical ICU. N Engl J Med. 2006;354:449-461.

39. Mascia L, Pasero D, Slutsky AS, et al. Effect of a lung protective strategy for organ donors on eligibility and availability of lungs for transplantation: A randomized controlled trial. JAMA 2010;304:2620-2627.
40. Youn TS, Greer DM. Brain death and management of a potential organ donor in the intensive care unit. Crit Care Clin. 2014;30:813-831.

41. Joseph $B$, Khalil M, Pandit V, et al. Hypothermia in organ donation: A friend or foe? J Trauma Acute Care Surg. 2014;77:559-563.

42. Kamarainen A, Virkkunen I, Tenhunen J. Hypothermic preconditioning of donor organs prior to harvesting and ischaemia using ice-cold intravenous fluids. Med Hypotheses. 2009;73:65-66.

43. Niemann CU, Feiner J, Swain S, et al. Therapeutic hypothermia in deceased organ donors and kidney-graft function. N Engl J Med. 2015:373:405-414.

44. Nijboer WN, Ottens PJ, van Dijk A, van Goor H, Ploeg RJ, Leuvenink HG. Donor pretreatment with carbamylated erythropoietin in a brain death model reduces inflammation more effectively than erythropoietin while preserving renal function. Crit Care Med. 2010;38:1155-1161.

45. Bouzat $P$, Francony $G$, Thomas $S$, et al. Reduced brain edema and functional deficits after treatment of diffuse traumatic brain injury by carbamylated erythropoietin derivative. Crit Care Med. 2011;39:2099-2105.

46. Cicora F, Stringa P, Guerrieri D, et al. Amelioration of renal damage by administration of anti-thymocyte globulin to potential donors in a brain death rat model. Clin Exp Immunol. 2012;169:330-337.

47. Cicora F, Stringa P, Guerrieri D, et al. Evaluation of histological damage of solid organs after donor preconditioning with thymoglobulin in an experimental rat model. Transpl Immunol. 2013;28:203-205.

48. Carlessi R, Lemos NE, Dias AL, et al. Exendin-4 attenuates brain deathinduced liver damage in the rat. Liver Transpl. 2015;21:1410-1418.

49. Carlessi R, Lemos NE, Dias AL, et al. Exendin-4 protects rat islets against loss of viability and function induced by brain death. $\mathrm{Mol}$ Cell Endocrinol. 2015;412:239-250.

50. Hoeger S, Fontana J, Jarczyk J, et al. Vagal stimulation in brain dead donor rats decreases chronic allograft nephropathy in recipients. Nephrol Dial Transplant. 2014;29:544-549.

51. de Ferrari GM, Schwartz PJ. Vagus nerve stimulation: From pre-clinical to clinical application: Challenges and future directions. Heart Fail Rev. 2011;16:195-203.

52. Yurcisin BM, Davison TE, Bibbs SM, Collins BH, Stamler JS, Reynolds JD. Repletion of S-nitrosohemoglobin improves organ function and physiological status in swine after brain death. Ann Surg. 2013:257:971-977.

53. Park ES, Son HW, Lee AR, et al. Inhaled nitric oxide for the brain dead donor with neurogenic pulmonary edema during anesthesia for organ donation: A case report. Korean J Anesthesiol. 2014;67:133-138.

54. Cardini B, Watschinger K, Hermann M, et al. Crucial role for neuronal nitric oxide synthase in early microcirculatory derangement and recipient survival following murine pancreas transplantation. PLoS One. 2014;9:e112570.

55. Koning AM, Frenay AR, Leuvenink HG, van Goor H. Hydrogen sulfide in renal physiology, disease and transplantation: The smell of renal protection. Nitric Oxide. 2015;46:37-49.

56. George TJ, Arnaoutakis GJ, Beaty CA, et al. Inhaled hydrogen sulfide improves graft function in an experimental model of lung transplantation. J Surg Res. 2012;178:593-600.

57. Lobb I, Davison M, Carter D, et al. Hydrogen sulfide treatment mitigates renal allograft ischemia-reperfusion injury during cold storage and improves early transplant kidney function and survival following allogeneic renal transplantation. J Urol. 2015;194:1806-1815.

58. Balaban CL, Rodriguez JV, Tiribelli C, Guibert EE. The effect of a hydrogen sulfide releasing molecule ( $\mathrm{Na2S}$ ) on the cold storage of livers from cardiac dead donor rats: A study in an ex vivo model. Cryobiology. 2015;71:24-32.

59. Nakao A, Toyoda Y. Application of carbon monoxide for transplantation. Curr Pharm Biotechnol. 2012;13:827-836.

60. Ozaki KS, Kimura S, Murase N. Use of carbon monoxide in minimizing ischemia/reperfusion injury in transplantation. Transplant Rev (Orlando). 2012;26:125-139. 